\title{
PEÇA TEATRAL COMO ABORDAGEM EDUCATIVA EM PRÁTICA EXTENSIONISTA PARA PREVENÇÃO E CONTROLE DO PIOLHO DE CABEÇA EM ESCOLA DE ARAUCÁRIA-PR
}

\author{
Steffano Alexsander Garcia de Paula \\ Universidade Federal do Paraná \\ steffanogarcia@gmail.com \\ Bruna Regina de Almeida \\ Universidade Federal do Paraná \\ brunareginadealmeida1993@gmail.com
}

Márcia Kiyoe Shimada Universidade Federal do Paraná mkshimada@gmail.com

Larissa Reifur

Universidade Federal do Paraná reifurla@ufpr.br

\section{Resumo}

O presente artigo tem como foco relatar e discutir a atividade realizada em uma escola da periferia da cidade de AraucáriaPR. O objetivo da atividade foi transmitir os conhecimentos sobre a pediculose, com ênfase no combate e prevenção, e desmistificar informações que vêm do conhecimento popular referentes a estas temáticas. O teatro foi a metodologia aplicada e apresentada para um total de 145 crianças, do pré-escolar ao quinto ano dos anos iniciais, e para um grupo de dez a 20 responsáveis. A atividade e a interação com o público foram bastante satisfatórias, uma vez que as crianças e responsáveis expuseram seus conhecimentos tradicionais prévios e foi possível por meio de um "bate-papo" corrigir alguns saberes arraigados sempre fundamentando em informações científicas.

Palavras chave: Pediculose Humana. Ectoparasitose. Combate. Teatro. Pediculus Humanus Capitis.

\section{THEATRICAL PERFORMANCE AS AN EDUCATIONAL EXTENSIONIST APPROACH ON PREVENTION AND CONTROL OF HEAD LICE IN A SCHOOL FROM ARAUCÁRIA-PR}

\begin{abstract}
This article focuses on reporting and discussing the activity carried out in a school on the outskirts of the city of AraucáriaPR. The objective of the activity was to transmit knowledge about combating and preventing pediculosis, and to demystify information that comes from popular knowledge regarding these themes. The theater was the methodology applied and presented to a total of 145 children, from preschool to the fifth year of the initial years, and to a group of ten to 20 parents. The activity and interaction with the public were very satisfactory, since the children and guardians exposed their previous traditional knowledge and it was possible, through a "chat", to correct some deep-rooted knowledge, always based on scientific information.

Keywords: Human Pediculosis. Ectoparasitosis. Combat. Theater. Pediculus Humanus Capitis.

\section{OBRA DE TEATRO COMO PRÁCTICA EXTENSIONISTA PARA ENSEÑAR LA PREVENCIÓN Y CONTROL DEL PIOJO DE LA CABEZA EN UNA ESCUELA DE} ARAUCÁRIA-PR
\end{abstract}

Resumen

Este artículo se centra en informar y discutir la actividad que se realiza en un colegio de las afueras de la ciudad de AraucáriaPR. El objetivo de la actividad era transmitir conocimientos sobre pediculosis, con énfasis en combatir y prevenir, y desmitificar la información que proviene del conocimiento popular sobre estos temas. El teatro fue la metodología aplicada y presentada a un total de 145 niños, desde preescolar hasta el quinto año de los años iniciales, ya un grupo de diez a 20 padres. La actividad e interacción con el público fue muy satisfactoria, ya que los niños y tutores expusieron sus conocimientos tradicionales previos y fue posible a través de un "chat" corregir algunos conocimientos arraigados, siempre basados en información científica.

Palavras clave: Pediculosis Humana. Ectoparasitosis. Combate. Teatro. Pediculus Humanus Capitis. 
Peça teatral como abordagem educativa em prática extensionista para prevenção e controle do piolho de cabeça em escola de Araucária-PR

\section{INTRODUÇÃO}

A pediculose é um quadro patológico caracterizado pela presença de ectoparasitos hematófagos conhecidos popularmente como "piolhos sugadores". Esses parasitos pertencem à subordem Anoplura (TRIPLEHORM et al., 2011), caracterizada pela presença de aparelho bucal sugador-pungitivo, família Pediculidae, a qual pertence o Pediculus bumanus capitis, conhecido como "piolho de cabeça" (MARCONDES, 2009).

O P. humanus capitis realiza seu ciclo biológico completo (ovo, ninfa, adulto) no couro cabeludo dos seres humanos, seus ovos são chamados vulgarmente de lêndeas (NEVES et al., 2016) e são fixados na base do cabelo (ALVES, 2018). A transmissão ocorre pelo contato direto com a cabeça de uma pessoa com piolho e pelo compartilhamento de fômites (MINISTÉRIO DA SAÚDE, 2016).

A manifestação clínica principal é o prurido frequente no couro cabeludo, podendo levar ao isolamento social e à influência negativa na aprendizagem (NOVAES et al., 2018). O caráter hematófago desse ectoparasito somado a uma má nutrição pode provocar quadros de anemia. É comum também as crianças infestadas apresentarem baixo rendimento escolar e distúrbios do sono devido ao incomodo da infestação (HEUKELBACH et al., 2003). Ademais, por estar erroneamente associada a um status socioeconômico baixo, a infestação pelo piolho pode ter um caráter vexatório no ambiente escolar, fazendo com que as crianças sintam vergonha ao serem examinadas. Pela mesma razão, adultos infestados costumam resistir ao exame da cabeça como método de diagnóstico (NUNES et al., 2015).

Como tratamento para pediculose há dois métodos mais aplicados: o químico, com a utilização de medicamentos, e o mecânico. O mecânico, feito por meio do pente fino, predomina em relação ao químico por combater as duas formas do parasito, adulto e ovo, tornando-se bastante vantajoso devido ao seu baixo custo e por ser difundido entre a população (PAGOTTI et al., 2012). O uso de fórmulas caseiras, como o vinagre, ainda é controverso, pois não há uma comprovação científica exata que garanta benefícios no combate à pediculose (CUMMINGS et al., 2018).

No Brasil, a prevalência de pediculose em crianças em idade escolar apresenta-se em torno de 30\% (BARBOSA et al., 2003). De acordo com Lustosa et al. (2020), na região metropolitana de Curitiba (cidades de Almirante Tamandaré e Lapa), a prevalência geral da pediculose em crianças em idade escolar atingiu cerca de 64\%. Costa et al. (2017) apontaram uma prevalência de 15,3\% de pediculose da cabeça em escolares da rede municipal de Divinópolis, Minas Gerais, além do problema de reinfestações nas crianças. Outra implicação relevante citada pelos autores é o impacto psicológico vinculado à infestação por piolhos. De acordo com as pesquisas, 50\% das crianças se 
Peça teatral como abordagem educativa em prática extensionista para prevenção e controle do piolho de cabeça em escola de Araucária-PR

revelaram envergonhadas quando os sinais clínicos da pediculose transpareciam, enquanto 20,8\% dos parasitados disseram sentir tristeza.

Dessa forma, optou-se por uma abordagem lúdica junto às crianças da escola, como o teatro, para desmitificar certas situações em relação à pediculose nesse trabalho extensionista. O teatro na educação é um processo que utiliza o drama como objeto de interatividade para ajudar no processo educacional. A teoria de aprendizagem social, descrita pelo psicólogo Albert Bandura, enfatiza a importância da aprendizagem através da observação, em que as crianças modelam comportamentos e atitudes. As performances teatrais são projetadas para estimular a participação e o debate entre as crianças, que se veem representadas através das estórias dos personagens, causando uma influência sobre o estado emocional e cognitivo delas, podendo conscientizá-las sobre decisões morais (WATERS et al., 2012).

Assim, a atividade intitulada "Prevenção e combate ao Pediculus bumanus capitis" abordou as principais características referentes à pediculose, dando ênfase ao combate e à prevenção, além de objetivar a desconstrução de diversos mitos e preconceitos. Por fim, optou-se pela elaboração da atividade e estabelecimento destes objetivos devido à recorrência de casos de pediculose nos escolares da instituição alvo.

\section{MATERIAIS E MÉTODOS}

\section{Características da instituição selecionada}

A escola escolhida para a intervenção pertence à rede municipal de ensino da cidade de Araucária-PR, e abrange um total de sete turmas, compreendendo 145 alunos com idades entre quatro a onze anos. No período matutino são atendidas quatro turmas (87 alunos) correspondentes ao segundo, terceiro, quarto e quinto anos; e no período vespertino são atendidas três turmas (58 alunos), que correspondem à pré-escola, primeiro e segundo anos. Há autorização dos responsáveis pelas crianças para o uso da imagem dos alunos, bem como o consentimento dos profissionais para uso das imagens para fins didáticos.

\section{Descrição da atividade}

A atividade faz parte do projeto de extensão "Promoção de Saúde Animal, Humana e Ambiental", sendo idealizada por dois graduandos do curso de Medicina, $5^{\circ}$ período (atual), da 
Peça teatral como abordagem educativa em prática extensionista para prevenção e controle do piolho de cabeça em escola de Araucária-PR

Universidade Federal do Paraná (UFPR). A ação aconteceu nos dias 25/09/2019 (manhã e tarde) e 25/10/2019 (noite).

Dessa forma, a atividade "Prevenção e combate ao Pediculus humanus capitis" foi criada a partir de reuniões com a diretora responsável pela escola. Nos encontros foram discutidas várias demandas apresentadas pela comunidade escolar que se enquadravam na abordagem do projeto de extensão "Promoção da Saúde Animal, Humana e Ambiental", assim, verificou-se o recorrente cenário de pediculose humana e a impossibilidade da diretora de tomar medidas além da permitida, que é comunicar a comunidade sobre casos de pediculose.

Posteriormente, elaborou-se um roteiro que norteou a atividade proposta, na qual foram abordados os conceitos principais sobre o combate à pediculose humana, bem como maneiras preventivas de evitar a transmissão do ectoparasito.

Foi realizado um teatro com um breve enredo pontual e interativo entre as personagens e o público-alvo que o assistia, o que possibilitou realizar perguntas para o público para poder obter informações sobre o conhecimento prévio dos alunos referente à temática. Também, realizou-se uma roda de conversa com os alunos, posteriormente à apresentação, de modo a dar abertura para que fizessem perguntas e esclarecessem as dúvidas.

Para a aplicação da atividade, o roteiro foi elaborado de acordo com a idade do públicoalvo. O enredo era sobre uma criança (Jojoba) que estava com piolho e recebeu ajuda de uma médica (Doutora Pentinho). Logo, possuiu dois personagens, 45 falas e uma paródia "Piolho, piolho" com um texto adaptado (Anexo I) do comercial do produto Escabin (COMERCIAL ESCABIN, 2007), no qual há os conceitos trabalhados sobre pediculose humana. Ao longo da peça, foram apresentados os conceitos científicos referentes à pediculose, de maneira lúdica, tais como: o que seria o piolho; os modos de transmissão (contato cabeça-cabeça e compartilhamento de objetos de uso pessoal como toalhas e acessórios), formas de combate (ênfase no uso do pente fino) e para o tratamento sempre procurar um profissional de saúde, sem abordagem de tratamento farmacológico durante a atividade.

Para o personagem infantil foi utilizado vestuário que remetesse a uma criança, tinta colorida para cabelo e boné. Na parte interna do boné foi colada a figura de um piolho em proporção aumentada em EVA (Fig. 1A), para demonstrar a transmissão através de fômites. Para a personagem médica foram usados um jaleco branco e um estetoscópio. Uma figura de um piolho em EVA marrom (Fig. 1B) representativa de um P. humanus capitis foi colada em um pente fino (Fig.1B) para demonstrar o método mecânico de retirada do piolho. 
Peça teatral como abordagem educativa em prática extensionista para prevenção e controle do piolho de cabeça em escola de Araucária-PR

Figura 1 - Representações de piolho usados em peça teatral apresentada na cidade de Araucária-PR em uma escola municipal. A) Ilustração de piolho em proporção aumentada em EVA marrom, foi colada em um boné para apresentar o método de transmissão através de fômites. B) Representação do piolho em EVA marrom colada no pente fino para representação da retirada do parasito pelo método mecânico e pente fino usado na atividade.
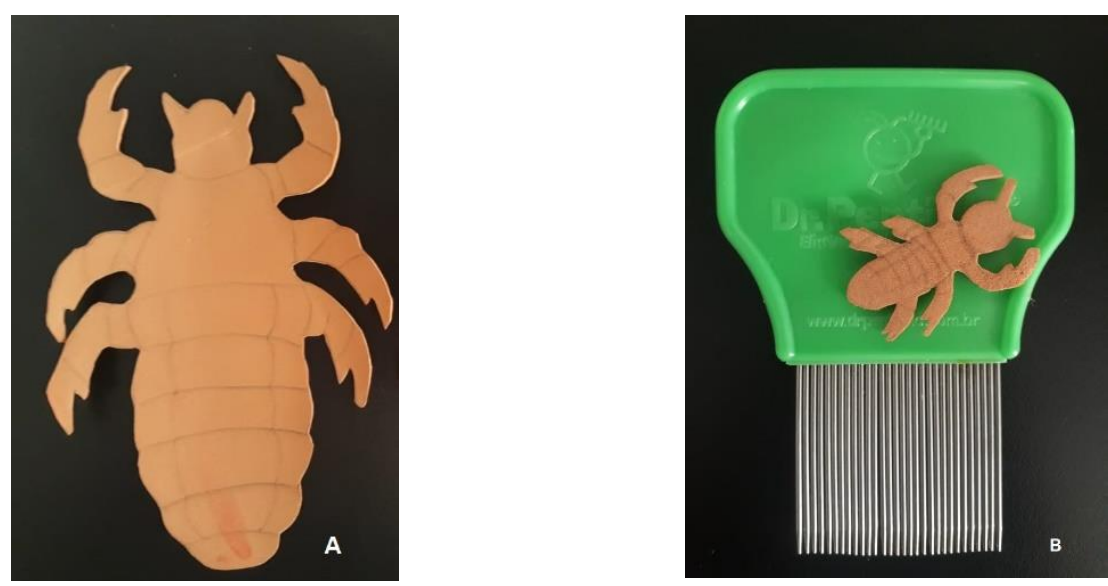

Fonte: o autor (2019)

Durante o período da manhã, a atividade foi apresentada para cada uma das quatro turmas, dentro da sala de aula, para aproximadamente 20-30 crianças por turma. Já no período vespertino do mesmo dia as três turmas foram reunidas, juntando, aproximadamente, 50 crianças, no pátio coberto da escola, todas sentadas no chão. Durante as apresentações, os alunos estavam acompanhados de seus professores regentes juntamente com professores extras e funcionários do serviço geral. A mesma atividade foi realizada em um terceiro momento, apenas com os pais ou responsáveis, em um dia posterior à interação com as crianças. $\mathrm{Na}$ apresentação para os pais ou responsáveis foi levada a mesma metodologia de apresentação, teatro lúdico e interativo, com o mesmo roteiro.

\section{RESULTADOS E ANÁLISES}

Participaram da atividade 145 alunos da escola alvo, sendo bastante colaborativos e interativos nos vários momentos em que lhes foi dada abertura. Havia muitos alunos que possuíam algum conhecimento básico referente à transmissão do piolho, no entanto, vários destes conhecimentos prévios relacionados à prevenção, transmissão e tratamento da infestação por piolho eram errôneos.

O primeiro grupo de alunos a participar foi do período da manhã, com 87 alunos presentes, divididos em quatro turmas, e a logística utilizada foi realizar a atividade do teatro em cada turma 
Peça teatral como abordagem educativa em prática extensionista para prevenção e controle do piolho de cabeça em escola de Araucária-PR

em separado. Nesse grupo, quando foi feita a apresentação para as turmas do segundo ano (Fig. 2), terceiro ano (Fig. 3), quarto ano e quinto anos, observamos as crianças bastante atentas em cada detalhe da peça e durante o processo de teatro interativo surgiram perguntas como: "O piolho é um carrapato?", "Mas se o piolho não voa e nem pula, como ele vai parar na cabeça da outra pessoa?", "Tem que raspar o cabelo quando pega piolho?”. Logo ao fim do teatro, no tocante às questões, buscamos sanar de maneira bastante direta e simplificada cada detalhe referente às perguntas e às características do parasito.

Referente ao método de combate, levantamos a questão ao fim da peça: "Vocês, sozinhos, sabem como combater o piolho?". Um tempo foi concedido para que eles pensassem e, logo, surgiram algumas formas de combate por meio dos conhecimentos populares adquiridos, como: "Minha mãe usa inseticida e coloca uma sacola na minha cabeça", "minha mãe passa vinagre". Apesar do vinagre causar a soltura das lêndeas aderidas, o que poderia facilitar a remoção com o pente fino (GABANI et al., 2010), não há comprovação científica da sua eficácia. Nesta atividade, o que se buscou foi mostrar aos alunos que o principal método de combate é o uso do pente fino, ao mesmo tempo que é necessário procurar uma unidade básica de saúde para o tratamento, pois nenhum método medicamentoso deve ser usado sem indicação médica.

Figura 2 - Imagem da peça teatral interativa sobre pediculose apresentada para quatro turmas dos anos iniciais de uma escola municipal da cidade Araucária-PR. Na foto, Dra. Pentinho apresentando o método mecânico de remoção do piolho da cabeça do personagem Jojoba para o segundo ano.

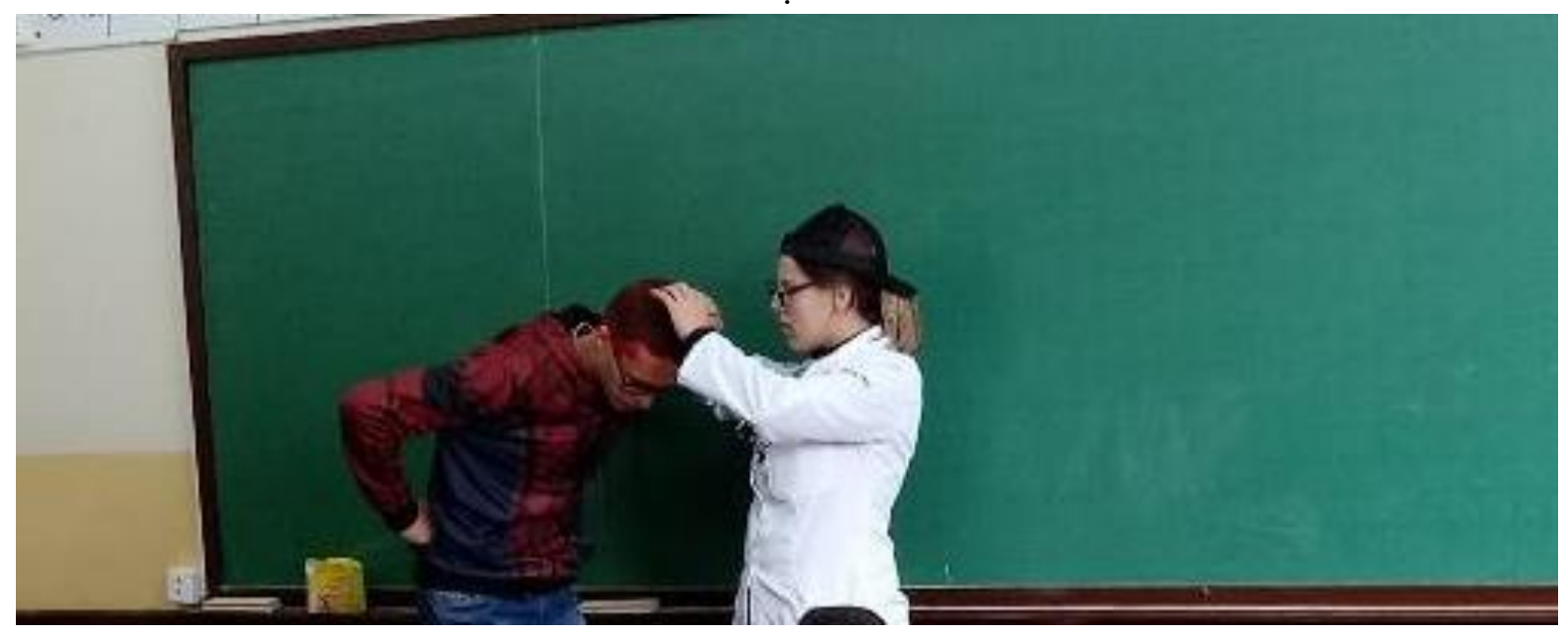

Fonte: o autor (2019) 
Peça teatral como abordagem educativa em prática extensionista para prevenção e controle do piolho de cabeça em escola de Araucária-PR

Figura 3 - Imagem da peça teatral interativa sobre pediculose apresentada para quatro turmas dos anos iniciais de uma escola municipal da cidade Araucária-PR. Na foto, Dra. Pentinho e o personagem Jojoba apresentando a paródia "Piolho, piolho" para o terceiro ano.

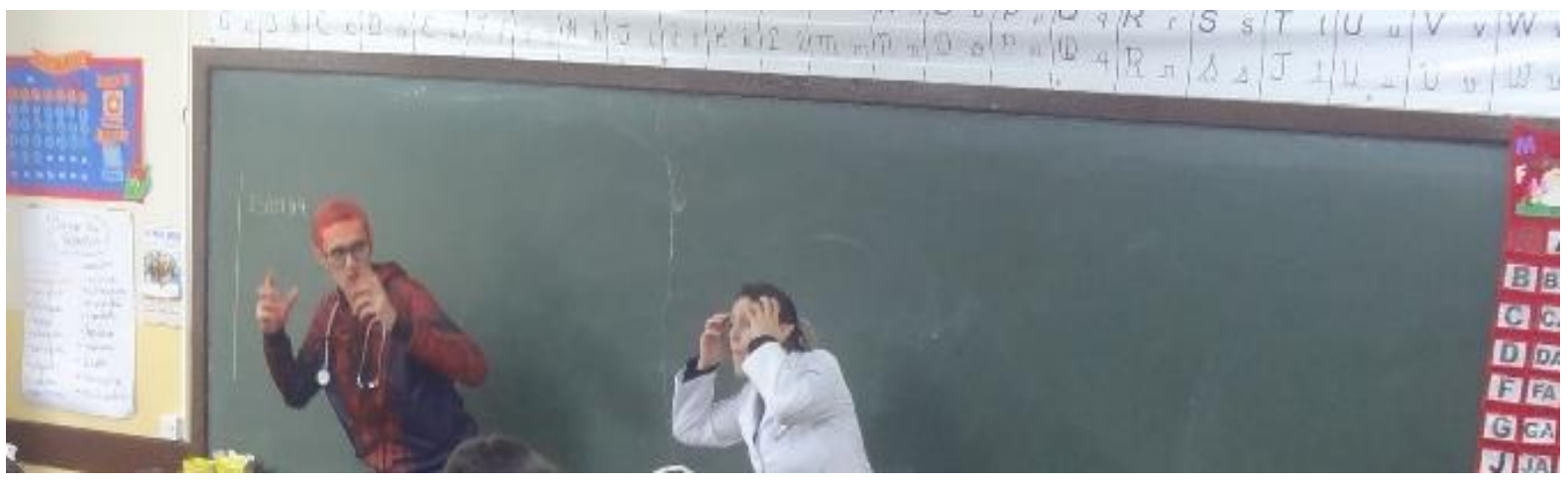

Fonte: o autor (2019)

O segundo grupo de alunos (Fig. 4) foi do período da tarde, com 58 alunos presentes, as três turmas foram reunidas em um único grupo no pátio coberto, todos sentados no chão. Ao fim da atividade, abrimos um momento de interação com a pergunta: "Vocês sabem como combater o piolho?", apesar disso, não tivemos muita interatividade no momento da abertura para perguntas devido à faixa etária dos alunos, porém, em todo momento eles ficaram focados e entusiasmados, apesar da idade e da quantidade de crianças no mesmo espaço, além da presença dos regentes de sala. Nesse caso, usamos o método da repetição, na qual fizemos com que eles repetissem alguns pontos-chaves abordados referentes à pediculose e também cantassem conosco a paródia "Piolho, Piolho" duas vezes (Fig. 5). 
Peça teatral como abordagem educativa em prática extensionista para prevenção e controle do piolho de cabeça em escola de Araucária-PR

Figura 4 - Imagem da peça teatral interativa sobre pediculose apresentada para duas turmas dos anos iniciais e para uma turma da pré-escola. Na foto, Dra. Pentinho na apresentação do método mecânico de remoção do piolho na cabeça do personagem Jojoba.

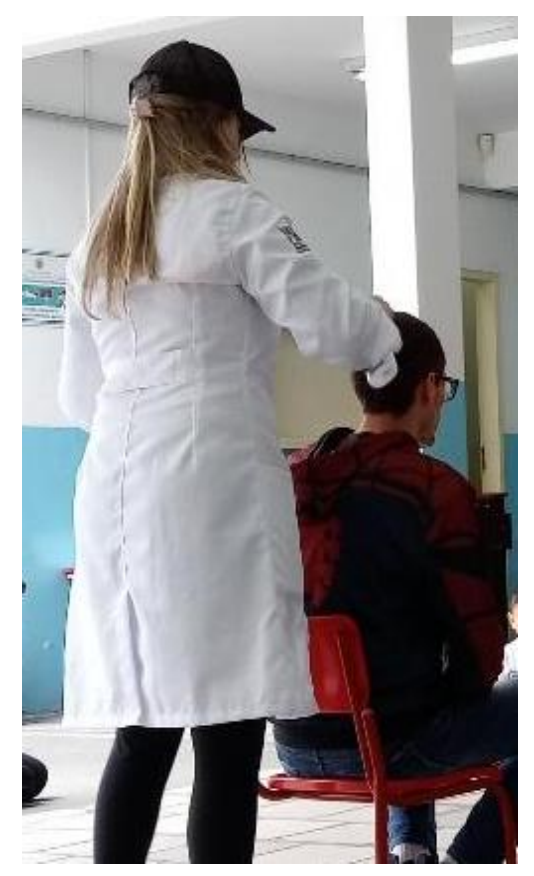

Fonte: o autor (2019)

O último grupo (Fig. 5) foi o dos responsáveis das crianças, esperávamos a presença de todos os responsáveis, no entanto, tivemos em torno de 20 responsáveis presentes. A abordagem com eles foi a mesma que aquela aplicada com as crianças, e, ao fim da atividade, abrimos um momento de interação com a pergunta: "Vocês sabem como combater o piolho?". As respostas foram as mesmas das crianças, então, fizemos a eles uma devolutiva do conhecimento transmitido pelas crianças para nós, demonstrando a transmissão da cultura tradicional, tendo por objetivo mostrar a importância dos responsáveis na construção dos conhecimentos e vivências das crianças (MAGALHÃES, 2018). Mesmo que, muitas vezes, o conhecimento tradicional seja algo benéfico à construção da personalidade e sobrevivência do indivíduo (SILVA et al., 2018), percebe-se que quando falta informatividade de fontes seguras há transmissão de saberes incorretos ou incompletos. Por fim, mostramos a eles os conhecimentos científicos referentes à pediculose que são eficazes. 
Peça teatral como abordagem educativa em prática extensionista para prevenção e controle do piolho de cabeça em escola de Araucária-PR

Figura 5 - Imagem da peça teatral interativa sobre pediculose apresentada aos responsáveis dos alunos que frequentam a escola municipal da cidade de Araucária-PR. Na foto, Dra. Pentinho observando a encenação do sintoma de prurido (coceira) no couro cabeludo em caso de pediculose apresentado pelo Jojoba.

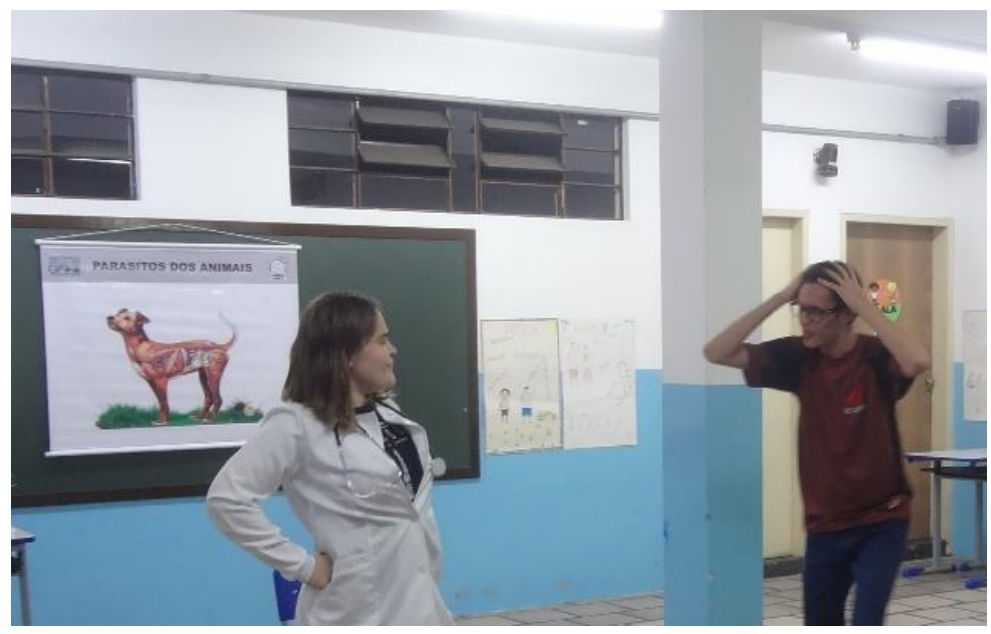

Fonte: o autor (2019)

Apesar de muitos dos participantes terem nos transmitido alguns conhecimentos tradicionais referentes ao combate, prevenção e tratamento da pediculose, um número reduzido dos participantes ressaltou o uso do método mecânico na remoção de piolhos, através do pente fino, como forma principal e mais eficaz.

Durante as atividades, quando levantamos questões socioeconômicas, como: "Vocês acham que apenas pessoas que não tem higiene adequada pegam piolho?", "Vocês acham que somente pessoas em situação econômica desfavorável são afetadas por piolho?" e "Vocês acham que o piolho prefere algum tipo de cabelo?”, a partir das respostas foi possível perceber alguns impactos sociais da pediculose, como a perpetuação de agravantes referentes à etnia e à vida socioeconômica.

\section{CONSIDERAÇÕES FINAIS}

A pediculose na atualidade ainda é bastante negligenciada pelos órgãos responsáveis (JAMANI et al., 2019) pelo cuidado com a saúde pública, no que tange a fatores e à educação em saúde, visto que muitas pessoas, além de sofrerem com os efeitos físicos da pediculose, ainda sofrem com o preconceito velado referente a essa doença, ainda que a pediculose não esteja ligada a fatores socioeconômicos (FRANKOWSKI et al., 2002). Na escola foi possível perceber, a partir dos relatos dos alunos, que o preconceito quanto à etnia e a fatores socioeconômicos são os principais agravantes do impacto social da pediculose. Isso demonstra que é necessário não só 
Peça teatral como abordagem educativa em prática extensionista para prevenção e controle do piolho de cabeça em escola de Araucária-PR

transmitir o conhecimento científico sobre a pediculose, mas também a desconstrução desses pensamentos ideológicos bastante discriminatórios, o que a atividade buscou desmitificar.

Quando foi analisado o conhecimento prévio das crianças referente à pediculose percebeuse a presença bastante forte do conhecimento tradicional, ou seja, aquele que a criança traz da educação familiar. Ainda que alguns nos afirmaram que os tratamentos caseiros oriundos dessa tradição fossem eficazes, o uso de muitas dessas soluções tradicionais permanece sem comprovação científica, ao mesmo tempo em que podem trazer consequências graves.

Sobre a metodologia usada, o teatro proporcionou transmitir as informações baseadas em conhecimentos científicos. É uma ferramenta adequada a qualquer faixa etária e pode abordar uma temática bastante séria de maneira leve e prazerosa, prendendo a atenção das crianças a cada detalhe, ao mesmo tempo que faz com que elas participem de forma ativa, interagindo com a equipe do teatro de maneira direta e de forma a desconstruir os mitos existentes referentes à pediculose.

\section{AGRADECIMENTOS}

Agradecemos à toda a equipe da Escola Municipal CECI Cantador, em especial à diretora Priscilla Cunha; às crianças e aos pais participantes das atividades; a todos os outros alunos integrantes do projeto de extensão da UFPR "Promoção da saúde animal, humana e ambiental". À Heloisa de Andrade, à Kamila Benevenuto Kaizer e à Victoria Cavalcanti, pela contribuição na escrita da introdução. À Leticia Fernandes de Carvalho e à Andreia Naiuf Lima Tuma, pela contribuição da aplicação e elaboração da cantiga da atividade na escola, respectivamente. À Próreitoria de Extensão e Cultura da UFPR, pelo financiamento (Edital PROEC/UFPR. 03/2019 Fortalecimento de atividades contínuas de extensão).

\section{REFERÊNCIAS}

ALVES, Caion (ed.). O que é Pediculose (Piolho), Tratamento, Remédios e Sintomas. Organização Pan-americana de Saúde 2018. Disponível em: https://opas.org.br/o-que-epediculose-piolho-tratamento-remedios-e-sintomas/. Acesso em: 30/04/2020.

BARBOSA, Júlio Vianna; PINTO, Zeneida Teixeira. Pediculose no Brasil. Revista Entomología y Vectores, v. 10, n. 4, p. 579-586. 2003.

COSTA, Cássia Cristina et al. Prevalência de pediculose de cabeça em crianças inseridas em centros municipais de educação infantil. Revista de Enfermagem do Centro-Oeste Mineiro, v. 7, 2017. Disponível em: http://seer.ufsj.edu.br/index.php/recom/article/view/1681. Acesso em: 20 Abr. 2020 https://doi.org/10.19175/recom.v7i0.1681. 
Peça teatral como abordagem educativa em prática extensionista para prevenção e controle do piolho de cabeça em escola de Araucária-PR

COMERCIAL Escabin (2007). FilmesVHS, Disponível em: https://www.youtube.com/watch?v=GQp4yy88DA4. Acesso em: 07 Jun. 2020.

CUMMINGS, Carl et al. Les infestations par les poux de tête: une mise à jour clinique. Jornal Paediatrics \& Child Health, v. 23, n. 1, p. 25-32. 2018. Disponível em: https://academic.oup.com/pch/article/23/1/e25/4860351. Acesso em: 30 Mai. 2020. https://doi.org/10.1093/pch/pxx166.

DEVERA, Rodolfo. Epidemiología de la pediculosis capitis en América Latina. SABER. Revista Multidisciplinaria del Consejo de Investigación de la Universidad de Oriente, v. 24, n. 1, p. 25-36. 2012. Disponível em: http://www.redalyc.org/articulo.oa?id=427739447012. Acesso em: 01 Jun. 2020.

FRANKOWSKI, Barbara L.; WEINER, Leonard B. et al. Piolhos. Jornal Pediatrics, v. 110, n. 3, p. 638-643. 2002. Disponível em: https://pediatrics.aappublications.org/content/110/3/638.short. Acesso em: 04 Mai. 2020.

GABANI, Flávia Lopes et al. Pediculose nos centros de educação infantil: conhecimentos e práticas dos trabalhadores. Revista Escola Anna Nery, v. 14, n. 2, p. 309-317. 2010. Disponível em: http://www.scielo.br/scielo.php?script=sci_arttext\&pid=S1414-

81452010000200014\&lng=pt\&nrm=iso. Acesso em: 29 Abr. 2020. https://doi.org/10.1590/S1414-81452010000200014.

HEUKELBACH, Jörg et al. Ectoparasitoses e saúde pública no Brasil: desafios para controle. Cadernos de Saúde Pública, Rio de janeiro, v. 19, n. 5, p. 1535-1540. 2003. Disponível em: https://www.scielo.br/scielo.php?script=sci_arttext\&pid=S0102-

311X2003000500032\&lng=pt\&tlng=pt. Acesso em: 01 Jul. 2020. https:// doi.org/10.1590/S0102311X2003000500032.

JAMANI, Shabana et al. Head lice infestations in rural Honduras: the need for an integrated approach to control neglected tropical diseases. International journal of dermatology, v. 58, n. 5, p. 548-556. 2019. Disponível em: https://onlinelibrary.wiley.com/doi/abs/10.1111/ijd.14331. Acesso em: 03 Jun. 2020. https://doi.org/10.1111/ijd.14331.

LUSTOSA, Bruno Paulo Rodrigues et al. Vaccuuming method as a successful strategy in the diagnosis of active infestation by Pediculus bumanus capitis. Revista do Instituto de Medicina Tropical de São Paulo. São Paulo, v.62, e7, 2020. Disponível em: https://www.scielo.br/scielo.php?script=sci_arttext\&pid=S0036-46652020000100202\&tlng=en. Acesso em 24 Mai. 2020. https://doi.org/10.1590/s1678-9946202062007.

MAGALHÃES, Odair do Nascimento. A importância da educação familiar e escolar na formação do homem: uma análise do ensino fundamental, na Escola Governador Sarney no município de Bacabal-MA. 2018.

MARCONDES, C.B. Doenças transmitidas e causadas por artrópodes. Rio de janeiro: Editora Atheneu, $1^{\mathrm{a}}$ ed., 2009.

MINISTÉRIO DA SAÚDE (Brasil). Fundação Oswaldo Cruz. Pediculose da cabeça (piolhos). In: Pediculose da cabeça (piolhos). [S. l. $], 2$ fev. 2016. Disponível em: https://bvsms.saude.gov.br/dicas-em-saude/2206-pediculose-da-cabeca-piolhos . Acesso em: 25 Mai. 2020. 
Peça teatral como abordagem educativa em prática extensionista para prevenção e controle do piolho de cabeça em escola de Araucária-PR

NEVES, D. P.; MELO, A. L.; LINARDI, P.M.; VITOR, R. W. A. Parasitologia humana. São Paulo: Editora Atheneu, $13^{\circ}$ ed., 2016.

NOVAES, Ana Karine Brandao et al. Parasitoses intestinais e pediculose: prevenção em crianças na idade escolar. Revista de APS. v. 20, n. 3, p. 444-449. 2018. Disponível em: https://periodicos.ufff.br/index.php/aps/article/view/16010. Acesso em: 23 Abr. 2020. http://dx.doi.org/10.34019/1809-8363.2017.v20.16010.

NUNES, Suellen Cristina Barbosa et al. Piolhos em amostras de cabelo de jovens, adultos e idosos em Manaus, Amazonas, Brasil. Revista do Instituto de Medicina Tropical de São Paulo. v. 57, n. 3, p. 239-244. 2015. Disponível em: https://www.scielo.br/scielo.php?script=sci_arttext\&pid=S0036-

46652015000300239\&lng=en\&tlng=en. Acesso em: 15 Jun. 2020. http://dx.doi.org/10.1590/S0036-46652015000300010.

PAGOTTI, Renata Elizabete; SANTOS, Verônica Pugliani dos; BISSON, Gabriela Silva; SANTOS, Milena Jorge Simões Flória Lima; FERREIRA, Beatriz Rossetti. Avaliação de um programa para controle de pediculose em uma escola [Evaluation of a program to control pediculosis in schools]. Revista Saúde \& Transformação Social/Health \& Social Change. v. 3, n. 4, p. 76-82, 2012. Disponível em: http://incubadora.periodicos.ufsc.br/index.php/saudeetransformacao/article/view/1823.

Acesso em: 14 Jun. 2020.

SILVA, Maria Laura Souza et al. Conhecimento tradicional como instrumento para dinamização do currículo e ensino de ciências. Revista Gaia Scientia. v. 12, n. 4, p. 90-104. 2018. Disponível em: https://periodicos.ufpb.br/ojs2/index.php/gaia/article/view/38710. Acesso em: 18 Jun. 2020. https://doi.org/10.22478/ufpb.1981-1268.2018v12n4.38710.

TRIPLEHORM, C.A.; JONNSON, N.F. Estudo dos insetos. São Paulo: Editora Cengage Learning, 2011.

WATERS, Stacey; MONKS, Helen; AYRES, Jennifer; THOMSON, Shane. O uso do teatro na educação (TIE): uma revisão das evidências. 2012. Disponível em: http://www.ntccorporate.com.au/wp-

content/uploads/2011/11/ECU_the_use_of_theatre_in_education_a_review_of_the_evidence. pdf. Acesso em: 20 Mai. 2020

Recebido em: 26/08/2020

Aceito em: 13/08/2021 


\section{ANEXO - Paródia "Piolho, piolho"}

Piolho, piolho

(Adaptado - Comercial do Escabin)

Piolho, piolho, coça, coça, coça sim

Para acabar com o piolho passa o pentinho sim

Se a cabeça coçar, coçar sem parar, acho bom ficar de olho porque pode ser piolho (2X).

Piolho, piolho, coça, coça, coça assim.

Para acabar com o piolho, passa o pentinho SIMMMMMM. 